\title{
AN INTER-SEMIOTIC STUDY OF IDEOLOGY ON THE BOOK COVERS OF PERSIAN TRANSLATIONS OF GEORGE ORWELL'S ANIMAL FARM
}

Amin Amirdabbaghian ${ }^{1^{*}}$

Krishnavanie Shunmugam ${ }^{1 * *}$

${ }^{1}$ University of Malaya, Kuala Lumpur, Malaysia

\begin{abstract}
All the movements and revolutions in the world's history have been initiated and reinforced by a systematized structure of standards, opinions and thoughts establishing the foundations of political, social or economic perspectives known as ideology. Ideology plays a vital role when the dimension of translation is added to the argument, for in addition to the author's ideas and attitudes of the world, the translator's beliefs and value systems as the medium between two cultures come to bear upon the translated product. In Iran, the 1979 Islamic revolution changed the ideological system from the secular to a markedly religious (Islamic) one, and this has increasingly influenced the way in which the cultural products are produced and/or translated. George Orwell's Animal Farm (1945) is one of the most retranslated novels in both the pre- and postrevolution era in Iran. This article presents a semiotic analysis on the book cover of Orwell's novel and its Persian translations at both the linguistic and illustration information level based on Serafini and Clausen's (2012) model of typography as a semiotic resource as well as Kress and Van Leeuwen's (2006) model of semiotic analysis. The book cover of two Persian translations of Animal Farm which have been produced in the pre- and post-revolution era, that is, by Amirshahi (1969) and Hosseini and Nabi Zadeh (2003) respectively, will be compared in relation to the cover page of Orwell's original novel. The findings reveal some distinct differences in the design of the book covers which represent a particular set of values, beliefs or ideology.

Keywords: Translation, Semiotics, George Orwell, Animal Farm, Persian
\end{abstract}

\footnotetext{
Ph.D. candidate in Translation Studies at Faculty of Languages and Linguistics, University of Malaya, Kuala Lumpur, Malaysia. His e-mail is: amirdabbaghian@siswa.um.edu.my ORCID: 0000-0001-6503-8446.

" Senior Lecturer at the Faculty of Languages and Linguistics at University of Malaya, West Malaysia. Her areas of expertise are Translation Studies, English Literature and Stylistics. Her e-mail is: krishnav@um.edu.my. ORCID: 0000-0002-4365-6187.
} 


\section{Introduction}

Research in Translation Studies has been increasingly interdisciplinary over the past two decades (Ning, 2003; Cem Odacioğlu \& Köktürk, 2015; Kourdis, 2015; Ožbot, 2015; Ehrensberger-Dow, Göpferich \& O’Brien, 2015; Akman, 2017) giving rise to new developments in translation theories, models and sub-branches of translation research (Salmani \& Eghtesadi, 2015). Translation theories are built upon other fields of study closely allied with translation work, for example, Registers in Communication Studies, Media Studies, and Discourse Studies, etc. In this study, typography and semiotic analysis models which are proposed by visual media scholars are adapted to carry out a study on inter-semiotic translation with the aim to identify ideology expressed by publishers on book covers.

Visual texts like written texts have incredible potential to create and represent new meanings and ideologies. The art of the cover design can represent the book as a whole. Matthews and Moody $(2007$, p. 19) believe that the cover or jacket of a book "conveys a message about the contents of the volume, influencing both the retailer who stocks the book and the potential purchaser in the shop".

The data sample of this study are cover pages of George Orwell's (1945) Animal Farm and the Persian translations of the novel by Amir Amirshahi (1969) as well as Hosseini and Nabi Zadeh (2003) from the pre- and post-revolution eras in Iran respectively.

\section{Definitions of Ideology}

Hawkes (1996) published a book on the general concept of ideology at a time when political and philosophical developments spread substantial hesitancy on the use and value of ideology. This book argues for a particular understanding of ideology as a description of the very conditions which have brought the notion of ideology into question. Hawkes (1996 p. xi) states that "the most convincing accounts of ideology have portrayed it as a false consciousness resulting from the belief in the autonomy and determining the power of representation". He claims that this belief is characteristic of and analogous to, though not necessarily determined by, market capitalism, and it traces a consistent historical pattern in the various critiques to which this mental tendency has been subjected since the beginning of the capitalist era. Hawkes does not attempt to catalog the infinity of definitions which has been offered for the term ideology but instead argues for the historical primacy, philosophical validity, and continued postmodern relevance of one particular definition.

Van Dijk (1998) states that ideology had a positive interpretation, similar to psychology when it was first introduced, but at present ideology has become an unclear concept, mainly referring to politics and beliefs of a specific group of people. He highlights that Marxist and non-Marxist schools of thought were the main influencing factors in politicizing the approaches towards ideology. Van Dijk generally defines ideology as the principles of the main group as it would 
have been regarded by traditional Marxist sociologists. Alternatively, he holds a broader outlook and defines ideology as a set of mutual principles generally shared and established by a group of individuals. His more specific definition of ideology is, "the basis of the social representations shared by members of a group" (1998, p. 8). This means that ideologies allow people, as group members, to establish a set of social beliefs about what is good or bad, right or wrong, for them, and with this, to act accordingly.

In his theory, Van Dijk (1998, p. 5) presents three main elements to analyze ideology:

1. Society which encompasses "group interests, power, and dominance",

2. Discourse that is based on "language use which expresses ideologies in society, often involving concealment and manipulation",

3. Cognition, that includes "thoughts and beliefs which go together to create ideas".

Van Dijk's (1998, p. 69-70) model of ideology also outlines the following important social functions:

1. Membership: "Who are we? Where are we from? What do we look like? Who belongs to us? Who can become a member of our group?"

2. Actions: "What do we do? What is expected of us? Why are we here?"

3. Values and norms: "What are our main values? How do we evaluate ourselves and others? What should (not) be done?"

4. Beliefs and goals: "Why do we do this? What do we want to realize?"

5. Relationships with other groups: "What is our social position? Who are our enemies, our opponents? Who are like us, and who are different?"

6. Resources: "What are the essential social resources that our group has or needs to have?"

\section{Ideology in Orwell's Animal Farm}

Animal Farm is Orwell's first highly acclaimed novel, which was published on the "heels of the World War II" in England (Amirdabbaghian and Solimany, 2013, p. 282). Amirdabbaghian and Solimany describe the novel as a fairytale where Orwell employs animal characters in order to "draw the reader away from 
the world of current events into a fantasy space where the reader can grasp ideas and principles more crisply" (p. 282). Orwell's allegorical novel is a commentary on the former Soviet Union. The exploitation of the proletariat by the rich is symbolized in the novel via the exploitation of animals by humans and Orwell analyzes Marx's theory from the animals' viewpoint.

Orwell also refers to the Tehran Conference as a strategic incident in his novel. The conference was held from November 28 to December 1, 1943, during World War II, in the embassy of the Soviet Union in Tehran, Iran (Gellately, 2013). It was an important assembly between the Big Three Allied Leaders that is, the President of the United States, Franklin D. Roosevelt, the British Prime Minister, Sir Winston Churchill and the Premier of the USSR, Joseph Stalin (Gellately, 2013). The main reason for this conference was the opening of the second front in Western Europe, specifically Nazi Germany (Gellately, 2013). The failure of the Allies, the two great Western powers and the USSR, to come to an agreement at the Tehran Conference was the main reason for the Cold War (Hosseini and Nabi Zadeh, 2003). Orwell ends Animal Farm on a "loud note of discord" with reference to this Cold War (Hosseini and Nabi Zadeh, 2003, p. 158).

It should be noted that Animal Farm is written in the third person narrative and varies from Orwell's previous novels in its fictitious personality as well as its dissimilar perspective on ideology. Animal Farm made it possible for Orwell to take his ideology a step further to reflect on the influences and threats of dictatorial systems.

\section{Background on the Persian Translators of Animal Farm}

Amir Amirshahi (dates of birth and death are unavailable) is an unknown translator as there is absolutely no record of information about him except for his name on the pre-revolution translation of Animal Farm. Based on his translation, however, it can be safely concluded that he supported the political ideology of the left-wingers and was a member of the opposition before the Islamic revolution in Iran, since he was interested in translating Orwell who was in favor of left-wingers.

Saleh Hosseini, who is the post-revolution translator, was born in $1946 . \mathrm{He}$ graduated from the George Washington University, USA, with a $\mathrm{PhD}$ degree in English Literature (Islami, 2003). He produced a translation of Orwell's Animal Farm in 2003 while working as a full-time university lecturer of Languages and Linguistics at the Shahid Chamran University of Ahvaz, Iran (Islami, 2003). Presently, he is a retired professor of Linguistics at the same university. Hosseini was nominated as the leading critic and translator of the year and the principal servant of publication in 1997 and 2003 by the Ministry of Culture and Islamic Guidance (see the portal of Shahid Chamran University of Ahvaz, 2018). Hosseini, as stated in his introduction to the Persian translation of Orwell's Nineteen Eighty-Four, does not profess allegiance to any specific political group or ideology, but he believes that manipulation in language use is an important factor influencing ideology which is evident in the Persian translations of Orwell's works (Hosseini, 1982). 
Masoumeh Nabi Zadeh, whose name is mentioned together with Hosseini's on the book cover of the Persian translation of Animal Farm, is said to have "contributed towards a few parts of the translation as an editor" (Khorsand and Salmani, 2014, p. 231).

\section{Book Covers}

Book covers provide a visual summary of the content of a book for potential readers. The cover of a book contains both verbal and visual elements. Verbal elements comprise the name/s of the author/s/translator/s/editor/s, the title, blurbs, the publisher's name, etc. which are called typographical information. Visual elements are drawings, photographic images, and illustrations which are called image information. Genette (1997) classifies all of these elements under the concept of peritext.

The first impression of a book in readers' minds is usually linked to the illustration of its cover. A certain message can be conveyed to the readers by carefully choosing the setting, lighting, clothing, depiction of characters and so on in the cover design. Matthews and Moody (2007, p. xx) highlight that "a test of the importance of the jacket to the marketing of books" is evident on how "the repackaging of books impacts on the kinds of readers they reach and the way in which they are valued". A research which was conducted for the Orange Prize for Fiction in the United Kingdom shows that "if knowledge of the author or book is excluded, the cover is the most important factor in whether readers would like to start reading a book" (Matthews and Moody, 2007, p. 23).

Sonzogni (2011) states that book covers reveal the cultural beliefs of the authors, designers, and readers. This study aims to understand the beliefs or ideologies (be it cultural, political, religious etc.) of publishers and authors by analyzing the book covers of Orwell's Animal Farm in comparison to two Persian translations of the novel published before and after the Iranian revolution.

\section{Past Studies on Inter-Semiotic Translation}

Research on book cover designs in relation to semiotics as a type of translation is very much an uncharted territory, since the only theoretical framework for research in this area lies far back in 1950 (Sonzogni, 2011). Jakobson (18961982) in his book, On Linguistic Aspects of Translation, lists three different types of translations, where the third type is inter-semiotic translation or transmutation. Inter-semiotic translation is "an interpretation of verbal signs by means of signs of non-verbal systems" (Jakobson, 1959/2004, p. 114). The examples Jakobson provides for inter-semiotic translation are "music-based fairytales", "[the] film adaptation of novels", "audio description" and "sign language interpretation". Jakobson's inter-semiotic translation is a similar process to Gambier's (2004) tradaptation (Williams, 2013, p. 9). In Torop's (2013, p. 241-242) view, the semiotic shift in translation studies introduced by Jakobson brings intra- and interlingual 
translation "closer to each other" and requires a new look at "translatability and the main ontological characteristic of a translational text - plurality". Below are a handful of studies which have investigated semiotics in literary works.

Korepanova (2013) explored the bodily in autobiographies in her dissertation. She examined four different autobiographical book cover designs in terms of intermediality to find out the link between the text and the photo image on the book covers. Korepanova assessed both the book covers as well as the textual materials based on the theory of performative. Korepanova argues that the self-representation of the bodily in the autobiographical textbooks reinforces in the audience's minds the unconditional autobiographical truth since the photographic image of the author on the cover alongside the autobiographical text creates the illusion of trustworthiness.

Salmani and Eghtesadi (2015) employed the inter-semiotic approach to the translation of book covers in retranslated novels. They applied Kress and Van Leeuwen's (2005) model of semiotic analysis on the cover design of Nathaniel Hawthorn's The Scarlet Letter (2004) and its three Persian translations. The analysis revealed that the cover design of the Persian translations had been changed. Salmani and Eghtesadi also confirmed that the translators had no role in designing the covers but the publishers or more so the commissioners "determined the elements which were presented on the cover or made a decision about their order or other aspects of the cover design" (p. 1185). Salmani and Eghtesadi point out culture and social ideologies as the obvious influential factors in cover designs in Iran "depending on the topic of a text, its genre and communicative process" (p. 1185).

Bailey (2017) carried out a semiotic analysis on the character, Nancy Drew on twelve book covers in nine Nancy Drew series published from 1930 to 2016. He applied the theory of representation introduced by Goffman (1979) to "explore [the] symbolism present in the covers and identify signs" (p. 21). Bailey used semiotic theory to break down the signs into both the signifier and the signified in order to better understand the intended meaning. He also used Goffman's theory to categorize messages derived from the research into dichotomies of masculinity/ femininity and dominance/submission. Bailey concluded that the representation of Nancy Drew had transformed through time from an independent and strong female character into a more dependent and weaker one.

\section{Scope of the Study and Research Framework}

The corpus for the semiotic analysis in this study is the cover design of Orwell's Animal Farm (1945) and the cover designs of its Persian translations in pre- and post-revolution Iran. This study considers semiotic analysis as a part of the paratextual analysis as put forth by Genette (1997), who divides paratextual materials into peritexts and epitexts. Peritexts are supplementary materials physically surrounding the book. Peritexts can be divided into two categories: 
1. Author/translator/editor's peritexts, which include introductions, prefaces, forewords, essays, etc.

2. Publisher's peritexts which include spins, back and front cover, list of other works by the author/translator, inside flaps, blurbs and the title page.

Similarly, Farahzad (2012, p. 43) states that the semiotic level includes all the "visual signs" surrounding the text, which include book covers, in-text illustrations, and visual images, fonts, layouts, colors and logos (in advertisements and websites). Visual signs provide information about the text as well as function as a representation mode. In Farahzad's (2012) view, these visual signs can manifest certain ideologies.

The front cover of the original novel, as well as that of the Persian translations, will be contrasted and discussed at the linguistic (typography) and illustration (image) information levels. The Linguistic Information (Typography) of the covers will be categorized and discussed based on Serafini and Clausen's (2012) model of Typography as Semiotic Resource. The Illustration Information (Images) will be categorized and discussed according to the Kress and Van Leeuwen's model for semiotic analysis.

Generally, typography refers to "the style, arrangement, or appearance of printed letters on a page" (Typography. (n.d.). Retrieved April 19, 2018, from https://www.merriam-webster.com/dictionary/typography). Linguistic Information in a book cover refers to the name of the author/s and translator/s and the title of the book which all can express an intended meaning (Kress and Van Leeuwen, 2006). Serafini and Clausen adapted their model from Machin (2007, p. 87) who sees the letterforms as an important "overall meaning of composition" which "have become more graphic and iconic". According to Serafini and Clausen (2012), typographical selections and typeface designs have meaning potentials and affect communication. Typography analysis can be done for both cover and content pages.

Serafini and Clausen (2012) list six elements under typographical features:

1. Weight refers to a "typographical feature that affects the appearance of a font, ranging from thin to bold, and is used to create emphasis in presentational formats" (p. 8).

2. Color is used as a typographical feature for "classifying, discriminating among design elements, and developing associations across compositional elements" (p. 9).

3. Size of a specific design feature and/or a visual component is used to "provide emphasis and add salience" to certain aspects of a compositional element and/or typographical feature (p. 10). 
4. Slant of a typographical element refers to "the slope of the letters, ranging from vertical to angled to the right or left" (p. 11).

5. Formality where the degree of formality of a font may add to the traits of a certain compositional element.

6. Flourishes or additions to a certain font "can add to its meaning potential" (p. 13). Formal flourishes can add a sense of formality while other additions add to the informality of the text (p. 13).

Once the book covers are analyzed for their typographical features, the illustrations will also be studied based on Kress and Van Leeuwen's (2006) model for semiotic analysis. Illustration refers to "a picture or diagram that explains or decorates” a book's cover (Illustration. (n.d.). Retrieved April 20, 2018, from https://www.merriam-webster.com /dictionary/illustration). The illustration analysis in this paper will look at six of the levels relevant to this study as proposed by Kress and Van Leeuwen (2006):

1. Frame and Setting are mental structures triggered by words and construct the worldview. These mental structures are part of the unconscious mind which automatically operate to make a sense of the world. The frame can both separate and connect certain visual elements in a multimodal set.

2. Color and Light as signifier and its meaning as "signified" contribute a certain ideology in recognizing the intended meaning.

3. Cultural, Historical and Social Reference are considered as tools to determine certain ideological implications by sign markers.

4. Logo Sign of the publishers represents the possible commissioner of the book. Logo sign can also show a bestselling novel.

5. Marked Sign is the nucleus and gist of the novel.

6. Elements of Storyline represented on the cover page of books help the viewers to distinguish the marked signs and understand their hidden ideological implications.

\section{Results and Discussions}

The images below are the front covers of the original Animal Farm as well as its pre- and post-revolution Persian translations, respectively. 


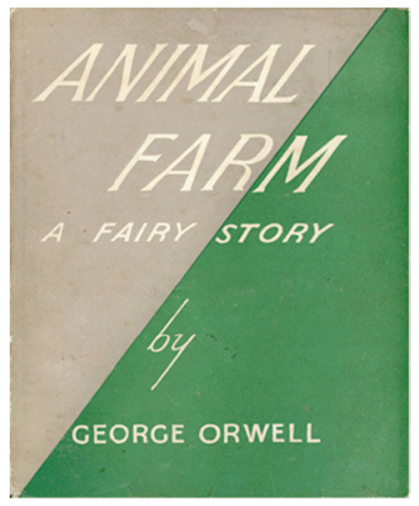

Animal Farm (1945) Secker and Warburg Publication, London, England.

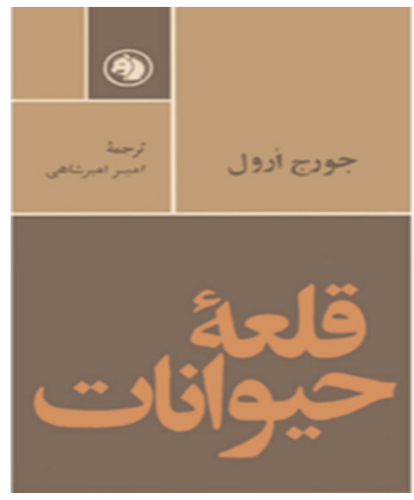

Animal Farm (1969) Trans. Amir Amirshahi, Jibi (pocket) Book Publishing Organization, Tehran, Iran.

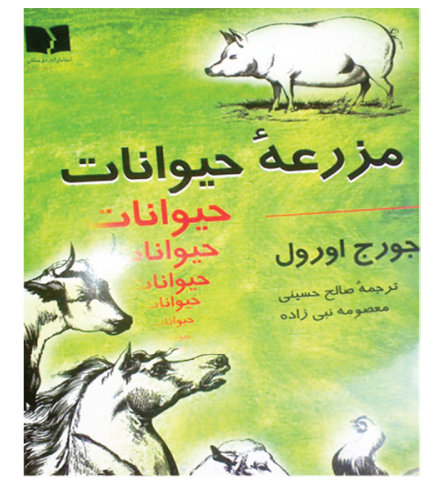

Animal Farm (2003) Trans. Saleh Hosseini and Masoumeh Nabi Zadeh, Doostaan Publication, Tehran, Iran.

In the original Animal Farm (1945), the only typographical features shared by the title of the novel, its subtitle and the author's name are that they are all written in the uppercase and in white color print which provides a formal outlook in line with the serious message embedded in the fictional novel. Orwell's allegorical satire was explicitly political; it was a statement against the failings of Stalinism and the dictatorial socialism of the Soviet Union.

Serafini and Clausen (2012) in relation to the "weight" of typographical features state that an increase in the weight of a font can increase the importance and/or the salience of "a particular typographical element in a multimodal ensemble" while thinning a font can possibly "diminish the attention" (p. 8). 
Under the "size" element, they further stress that larger elements attribute more salience since bigger words are noticed more readily than smaller ones. Also, a slant in the written form can also foreground one linguistic item over another which is presented without a slant.

A distinct contrast can be seen in the font weight and size, shapes as well as the position of the written elements on Orwell's original book cover. The title and subtitle are in bigger fonts than the author's name resulting in more salience given to the story. Likewise, the italicized titles which provide a visual slant suggest "a more dynamic presence or an increased level of energy" (Serafini and Clausen, 2012 , p. 11) compared to the author's name which sits in the conventional, unitalicized mold. Then, between the title and subtitle, clearly the main title takes prominence by being printed in a much larger font than the subtitle. While the subtitle, A Fairy Tale, is inserted to emphasize the fictitious nature of the story, it is still kept much smaller than the looming size of the main title to probably imply otherwise; that Animal Farm has a significant, weightier message behind what is claimed to be a fable.

The directionality of information and items structure can also manifest certain ideologies from the semiotic view (Kress and Van Leeuwen, 2006). The cascading of the main title in the largest slanted font, at the topmost position, to the subtitle in a comparatively smaller slanted font, in a fairly middle position, to the author's name in the smallest upright standard font, placed at the far bottom middle position, expresses the hierarchical importance or directionality of the written items on the cover page. This is unlike book covers like the ones below (written in the same era as Animal Farm) where the author's name is given greater prominence in terms of font size and placement or position compared to the book title itself:
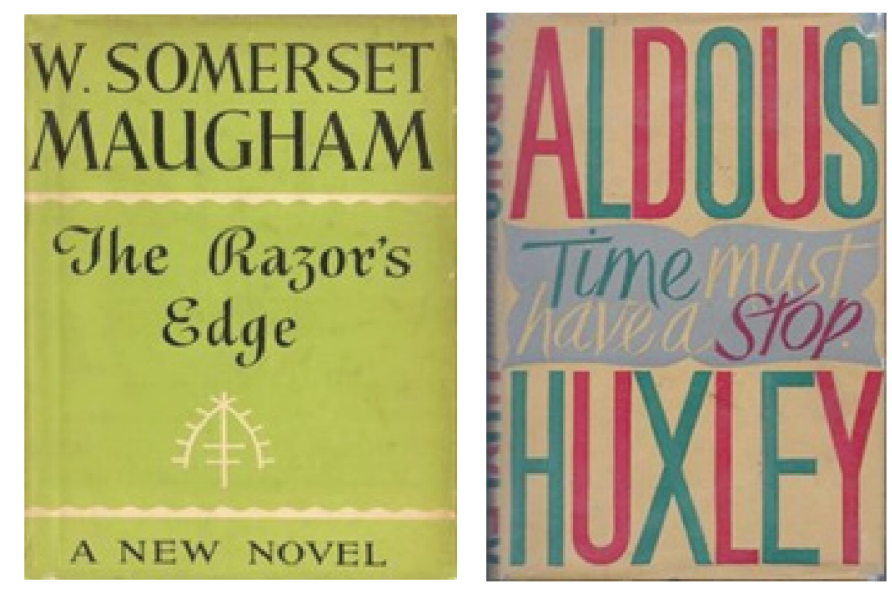

According to Kress and Van Leeuwen (2006), the setting is an element of a visual composition including visual shapes and colors. This includes borders and lines which are formal frames used to set off certain compositional elements. In Orwell's Animal Farm (1945), a diagonal line, from the top-right hand corner to the bottom-left corner, divides the front cover into two triangles with grey being the color of the upper left- hand triangle and an army or olive green filling the lower 
right-hand triangle. The diagonal line which splits the space into two separate dimensions, specifically triangles, represents the two conflicting ideologies of the world of the animals (socialism) and the humans (capitalism). Kress and Van Leeuwen (2006) discuss the meaning values expressed by cyclic shapes like circles and angular shapes like triangles in their book on visual grammar:

Circles and curved forms generally are the elements we associate with an organic and natural order, with the world of organic nature...

Angularity we associate with the inorganic, crystalline world, or with the world of technology, which is a world we have made ourselves, and therefore a world we can, at least in principle, understand fully and rationally. A triangle is angular, like the square - an element of the mechanical, technological order. (2006, p. 54-55)

The two triangles on the book cover as such do not represent the world of organic nature but ones created by humankind and striving against each other, i.e., the capitalist economy, where specific individuals or businesses have monopoly of production and profits, against the socialist economy, where the ideal is for everyone to be equal owners of the factors of production.

Kress and Van Leeuwen (2006) stress the fact that color has always been used as a semiotic resource although it has never been a unified system, owing to different cultures having varied value systems; they state that debates about color symbolism have existed since the Middle Ages. Serafini and Clausen state that color is connected with certain emotions and social meanings; that it is a semiotic resource used for "expressing and communicating meaning potentials in social contexts and cultures" (2012, p. 9).

The title, subtitle and author's name on the book cover of Animal Farm are all in white as mentioned earlier. The color white in the Western world reflects openness and simplicity which has a positive connotation (Bleicher, 2012) against the grey in the left triangle and the khaki or military green in the right triangle. Grey, a neutral color which has negative and mysterious connotations in the Western culture (Bleicher, 2012), in the context of Animal Farm quite certainly symbolizes the bleakness of the political era Orwell lived in. Green, in general, refers to the color of life and energy with particular reference to the natural environment (Bleicher, 2012). However, the shade of green on the book jacket is not a bright, lively or pastel green but a saturated or dark green signifying a certain militancy in the psyche of both capitalism and corrupt socialism. Also, it is possible to see the green as an olive green which also stands for justice, hope and peace in certain contexts. It is possible that this too is an intent of the publisher and author, i.e., a hope for a better world in the midst of the bleakness of the political upheavals in the early 1940s.

A survey of Orwell's fictional or non-fictional writings published by Secker and Warburg, on the whole, show that the book covers of his publications only have typographical features and reveal a stark absence of visual images. Below are some of the book covers to highlight this observation: 

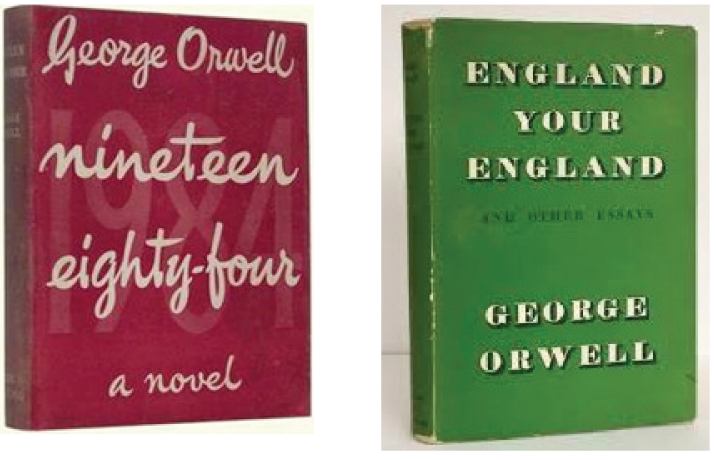
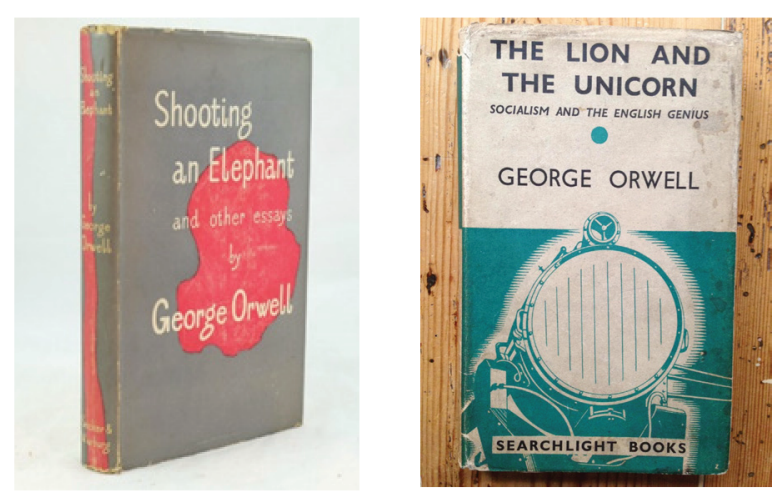

Secker \& Warburg was established in 1936 from the merger of the firms Martin Secker and Frederic Warburg. The British publishing company was known for its anti-fascist and anti-communist political stance, which stood out against the political spirit and culture of many intellectuals of the time. Apart from Orwell's writings, Secker also published other anti-Stalinist authors which included C. L. R. James, Rudolf Rocker, and Boris Souvarine as well as works by Lewis Mumford. Secker \& Warburg were also prominent for introducing foreign writers such as Kafka, Mann, and Musil to the English readership. (https://www.biblio.com/ publisher/ martin-secker-warburg)

The only visual that can be seen in the examples above is in the book cover of Orwell's Lion and the Unicorn - Socialism and the English Genius (1950) but even this visual, which is the headlights of a train, is in fact a logo of Searchlight Books, a series launched by Secker \& Warburg in 1941 to publish a series of essays as hardback books. Orwell was one of the two editors of this series, which was short-lived due to a bomb damage that destroyed the printer's paper stock; only ten out of the proposed seventeen series were successfully published between 1941-1942. (https://www.biblio.com/publisher/ martin-secker-warburg)

Frederic Warburg was chairman of Secker and Warburg Ltd. from 1936-1971 and after his retirement served as president of the publishing house. Warburg and Orwell were close friends and the reasons are evident in the obituary written for Warburg which was published by The New York Times on May 28,1981:

He befriended Mr. Orwell and accepted "Animal Farm," a satire on life under totalitarian rule, in 1944 when other publishers rejected it on the ground that it might annoy the Soviet Union, Britain's then wartime ally. The novel eventually sold nine million copies. Mr. Orwell's next work, "1984," sold 11 million.

During World War II, Mr. Warburg and Mr. Orwell served together in the British Home Guard, the publisher as a corporal and the writer as his sergeant. (https://www.nytimes.com/1981/05/28/obituaries/fredricwarburg-dies-published-orwell-books.html)

It can be safely implied that the mutual dependence between Orwell and Warburg was an almost equal one. While Orwell was an important contributor to Secker \& Warburg's publications, it was Warburg who had helped materialize 
the publication of Animal Farm after eighteen months of rejections from other publishing houses and had subsequently seen through all of Orwell's publications. The presentation of the book cover for Animal Farm as such would have been an agreement between the publisher and author.

In the pre-revolution Persian translation of Animal Farm (1969), the cover page is divided into two big blocks with the lower part in the darkest shade of brown taking the bigger portion of the space to highlight the title of the book. The title is in a lighter brown color and in the largest font, thereby foregrounding it against the rest of the written elements. The upper portion is further divided into four parts - two squares and two rectangles of different sizes. Three of the parts are in yet another shade of brown while the smaller of the two squares takes the same dark background color of the bigger lower portion where the title sits. The logo of the publisher is imprinted in this smaller square.

The unequal sizes of the five parts in total reflect the sense of inequality of power which is one of the themes in Animal Farm. That this Persian version was published in an Islamic state also suggests the significance of five in the Islamic context, i.e., the five pillars of Islam, which are the five basic, mandatory rules all Muslims are taught to uphold.

Both Orwell's name and the translator's name, Amirshahi, are presented in a similar dark brown color but the translator's name is in a smaller font in contrast to the author's name, thus giving prominence to the original author. All the linguistic information on the cover is written in a standard Persian font, which expresses a tone of formality.

In Iranian culture, brown is a neutral color which is connected with the material world and lust, hatred and wrath (Ostovar, 2012). This aligns with the elements of the storyline of Animal Farm which progressively escalates into greed, betrayal, animosity and the loss of identity. Also, the different shades of brown imply different levels of evil, some being viler than others, like Napoleon the Commander pig, who is the cruelest amongst all the ruling animals. Moreover, the subtitle, A Fairy Story present in the original cover is starkly absent in this cover page. This is important since, in the Iranian perspective, there are parallels between the political state that Iran was imminently approaching at that time - a world similar to the one in Animal Farm (Shokri, 2011).

Amir Shahi (1969) also changed the target text title into "قلعها [qale'] (castle)" which is totally different from "farm" in the source text. Castle carries two different meanings. The first and oldest one is "a large building usually with high, thick walls and towers that was built in the past to protect against attack" and the new meaning is "a large expensive house" (Castle. (n.d.). Retrieved December 29, 2017, from https://www.merriam-webster.com/dictionary/castle). This shift in meaning in the translation of the title can be assumed as the translator's and publisher's criticism of the Iranian monarchy government before the Islamic revolution. By using castle, Amir Shahi (1969) intensifies both the martial and luxurious implications expressed by ' فلعه [qale'] (castle)'. Based on what is said by Abbas Milani (2011), in Chapter 13 of his book entitled, The Shah, Mohammad 
Reza Pahlavi (the former Shah of Iran) failed in fulfilling his promises to the people in what he called the "white revolution and land reforms"; the failed reform had thrown people under more economic pressure than in previous times while the Shah himself was enjoying living in luxurious palaces (Milani, 2011, p. 233-255). Van Dijk (1998) believes that the use of negative meanings shows one's perspectives and interests which reveals his/her ideological, social and political position. The substitution of "castle" for "farm" clearly show this ideological stance against the Shah at that time.

The pre-revolution Persian translation was published by Jibi (pocket) book publishing organization. Alinezhad (2016) reports that most of the pre-revolution books, which were published by Jibi book publishing had no specific cover design. Fadzlinezhad (2012) informs us that Jibi was a part of the American Franklin book program in Iran and was funded by the Iranian modernist intellectuals to spread leftist ideologies in pre-revolution Iran. The founders of the Franklin book program in Iran (like Homayoun Sanaatizadeh, Majid Roshangar, and Sirous Parham) believed in leftism as a way to be perceived as open-minded intellectuals in pre-revolution Iran (Alinezhad, 2016; Parham, 2018). In the late 1960s, Jibi book publishing turned into a joint-stock company, and then, Amirkabir publication bought major stocks off the company (Samii, 2014).

There are only three shades of brown on the cover page of the pre-revolution Persian version which give it a dour appearance. There is no other variation; no other primary or secondary colors are used. This bare simplicity and lack of vibrant colors in the cover page design of the pre-revolution translation express the ideological patronage, which in Lefevere's (1992) theory is a significant control factor. Lefevere (1985, p. 227) states that patronage is a power (person or institution) out of the literary system which "help or hinder the writing, reading and rewriting of literature" because of their prominent status or position in society. Jibi book publishing could be considered as one of the patronages in this context. In Lefevere's (1985) opinion, patronage is more interested in the ideology of the literature than the poetics, i.e., style or the understanding of how a text's different elements synthesize and produce certain effects on the reader. The book cover of Amirshahi's translation is therefore subject to Jibi's pocket book design without illustrations.

In the post-revolution Persian translation of Animal Farm (2003), the title is printed in black a little above the middle part of the cover and in the biggest font on the cover, giving it the most salience. Below the title, on the right-hand side, there is a thin red half-line. Below this half-line is the author's name in black and in a smaller font compared to the novel's title. Below Orwell's name, are the translators' names, Hosseini and Nabi Zadeh also in black but in a smaller font in contrast to the author's name. As in the pre-revolution cover page, here too the author is given greater importance than the translator, and the title more emphasis than the author's name and, the font is entirely formal without any flourishes. It must be noted that again as with the pre-revolution cover page, the post-revolution book jacket has also omitted the subtitle, A Fairy Tale for the same reason as discussed earlier. 
مelow the first word in the title, that is, directly under the word " حيو انات [heyvaanaat]" which means "animal", the word is rewritten vertically five times in a funnel shape in bright red color. In other words, heyvaanaat is repeatedly written with the effect of slowly diminishing itself in size. It must be noted that this only happens to the word, "animal" and not "farm". This draws attention to how the leaders of the animals (who represent socialism) start off well with noble ideals of equality but finally lose their selves and ideals to corrupt capitalism.

There are four distinct colors on this cover page - black, white, red and green. In the Iranian culture, black is the color of misery, disappointment, and misfortune and red refers to danger, victims and sacrifice (Ostovar, 2012). Red is also seen as the color of martyrdom (Schimmel and Soucek, 1992). The Doostaan publishers have obviously chosen symbolic colors as the both the red and black closely relate to the suffering, discrimination and execution of the "lesser" animals throughout the novel. The animals are all portrayed in white color as they represent the socialist idealists whose early intentions were genuine and pure. The bright green is in keeping with the farm theme but will also appeal to the Islamic readers who would recognize this as the color most associated with Islam. In fact, the cover page has the three colors that make up the colors of the Iranian flag, as can be seen below:

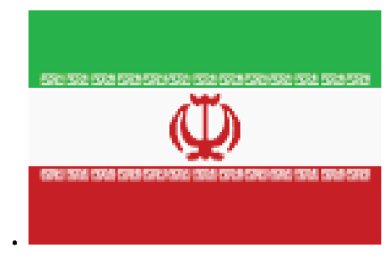

The green in the flag stands for Islam; the white for peace; and, the red for courage. The red symbol in the middle of the flag stands for the five principles of Islam (https://www.worldatlas.com/webimage/flags/countrys/mideast/iran. $\mathrm{htm})$. The Persian writing for "animal" printed in red signifies the suffering farm animals' courage to fight their treacherous human master (capitalism) via a revolution. The pre-revolution translation therefore depicts all the animals - the pig, the goat, the horse, the sheep and the rooster (all of which are characters in Animal Farm) in white, as these were the revolutionists fighting for a good cause - for peace, freedom and an equal share of prosperity. While in Islam white stands for peace, in Iranian culture, white also stands for death (Ostovar, 2012). Those who fight for peace inevitably face death, as do some of the animals in Animal Farm.

With reference to frame and setting, the pig is placed at the topmost righthand corner, while the other four animals are clustered together almost diagonally opposite at the bottom of the page from the left-hand to the right-hand corner. The pictures tie in with the title to provide an idea of the players in this story. The pigs emerged as the dictatorial leaders of Animal Farm after the rebellion. So, illustrating a pig at top of the cover is evidently to depict their dominance and superiority as leaders of the farm. The four animals at the bottom represent 
the inhabitants of the farm who were subject to the oppressive governance of the pigs. It is also significant that the faces of the animals at the bottom are turned away, looking to the right, away from the pig, which is also depicted as looking straight ahead with no eye-contact with the other animals. The message clearly is, that the animals are not equal and are disunited; this is a subversion of the seventh commandment of "Animalism" - "All animals are equal" which at the end is amended to "All animals are equal but some animals are more equal than others", so that the animals who disagreed with the pigs could be eliminated (which depicts Communism). The cows, as their milk was always stolen by the pigs, resemble the poor but devoted working class; the horses refer to the less educated but hardworking male citizens; the sheep represent the duped citizens of a totalitarian state; the rooster, representing the chickens, parallels the sailors at the Kronstadt military base who unsuccessfully rebelled against Communist rule (Moran, 2001, p. 49-54).

Despite a thorough search for information on Doostaan Publications, the publisher of the post-revolution version, no records were found. As such the publisher's ideological stance cannot be traced. However, in post-revolution Iran, all publications had to be approved by the Ministry of Culture and Islamic Guidance, also known as Ershad, which is responsible for restricting access to any influence (media, publications) that fails to comply with Islamic ethics or advocates values foreign to the Iranian Revolution. As such, it can be safely assumed that the Doostaan publishers would have been subjected to an Islamicoriented political stance.

\section{Conclusion}

Kress and Van Leeuwen state that "[v]isual structures...produce images of reality which are bound up with the interests of the social institutions within which the images are produced, circulated and read. They are ideological. Visual structures are never merely formal: they have a deeply important semantic dimension" (2006, p. 47). In the analysis of the book covers of Orwell's Animal Farm and its pre-revolution and post-revolution Persian translations, visual structures which consist of both typographical as well as drawings or illustrations were analyzed. The publishers' choices of font types, shapes and sizes, frame and setting with regard to placement or positioning of linguistic or graphic elements and color selections on the book covers (quite possibly with consultations from the author and translators) have revealed some of their ideological inclinations.

The book cover of the post-revolution Persian translation of Animal Farm stands in profound contrast to both the original book cover and the pre-revolution book cover due to its pictorial representations, varied use of symbolic colors very much associated with its Islamic context. The Iranian government is a religious theocracy which strictly enforces Islamic Shariah law and demands its people to pay obeisance to the Leaders of the Islamic Republic. Criticisms or insults of the slightest kind towards the Supreme Leader and his faithful servants is punishable 
by death or long-term prison sentences. The Iranian regime is therefore both totalitarian and authoritarian. Animal Farm adequately reflects the ideology of the Iranian regime and therefore what the publishers would have to be obedient to.

Warburg's book cover of Orwell's Animal Farm and Jibi's pre-revolution Persian publication of the novel are plain and sombre with no images and with the use of minimal colours. Though much more subdued in their visual portrayal than the post-revolution cover, these too express their ideological stance: Warburg and Orwell were anti-totalitarianism and Jibi publishers, who were leftists and who lived in a freer Iran in pre-revolution times, probably saw the imminent revolution as threatening as the story of Animal Farm. This is somewhat implied in the stern brownness of the book cover and the manner in which the space is mechanically boxed-in by five angular parts.

\section{References}

Akman, E. (2017, April). Çeviribilim Ve Tefsir Bilimin Disiplinlerarasi İlişkisi (Interdisciplinary Relationship Between Translation Studies and the Science of Tafsir]. International Journal of Languages' Education and Teaching, 5(1), 267-285. doi:10.18298/ijlet.1716.

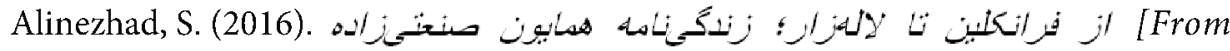
Franklin to Lalezar; A Biography of Homayoun Sanaatizadeh]. Tehran: Qoqnoos.

Amirdabbaghian, A., \& Solimany, S. (2013, December). The Application of Baker's Taxonomy on Translation of Literary Texts A Case Study of George Orwell's Animal Farm. International Journal of Science and Research (IJSR), 2(12), 280284.

Bailey, L. (2017, May). The Mystery of the Vanishing Sleuth: The Representation of Nancy Drew in Cover Design from 1930 to 2016. Unpublished MA Dissertation. Tennessee, USA: Middle Tennessee State University.

Bleicher, S. (2012). Contemporary Color: Theory \& Use (2nd ed.). New York, USA: Cengage Learning.

Cem Odacioğlu, M., \& Köktürk, Ş. (2015, July). From Interdisciplinarity to Transdisciplinarity in Translation Studies in the Context of Technological Tools \& Localization Industry. International Journal of Comparative Literature \& Translation Studies, 3(3), 14-19. doi:10.7575/aiac.ijclts.v.3n.3p.14.

Ehrensberger-Dow, M., Göpferich, S., \& O'Brien, S. (2015). Interdisciplinarity in Translation and Interpreting Process Research. Amsterdam: John Benjamins. doi:doi.org/10.1075/bct.72.

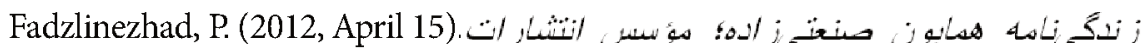

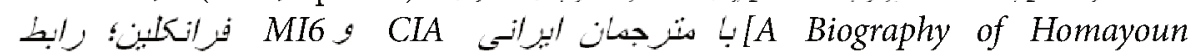
Sanaatizadeh; the Founder of Franklin Publication - An Agent between MI6 and CIA with Iranian Translators]. Retrieved March 05, 2018, from Fars News: http:// www.farsnews.com/newstext.php?nn=13910126000008.

Farahzad, F. (2012). Translation Criticism: A Three-Dimensional (Model Based on CDA). Translation Studies, 9, 27-44.

Gellately, R. (2013). Stalin's Curse: Battling for Communism in War and Cold War (Vol. 1st). Oxford, United Kingdom: Oxford University Press.

Genette, G. (1997). Paratexts: Thresholds of interpretation. (J. E. Lewin, Trans.) Cambridge: Cambridge University Press. 
Hawkes, D. (1996). Ideology. London \& New York: Routledge.

Islami, M. (2003). درباره نزجما هاى 1984 [About 1984 Translations]. Haft, 12-13.

Jakobson, R. (1959/2004). On Linguistic Aspects of Translation. In L. Venuti, The Translation Studies Reader (2nd ed., p. 113-18). London \& New York: Routledge.

Khorsand, M., \& Salmani, B. (2014, March). Anthems as Propaganda: A Discoursal Translation Quality Assessment. International Journal of Language Learning and Applied Linguistics World (IJLLALW), 5(3), 222-237.

Korepanova, A. (2013). Judging a Book by its Cover: The Manifestation of the Bodily in Contemporary Autobiography. Unpublished MA Dissertation. Lund, Sweden: Lund University.

Kourdis, E. (2015). Semiotics of Translation: An Interdisciplinary Approach to Translation. In P. P. Trifonas, International Handbook of Semiotics (p. 303-320). New York: Springer. doi:10.1007/978-94-017-9404-6.

Kress, G., \& van Leeuwen, T. (2006). Reading images: the grammar of visual design (2nd ed.). New York: Routledge.

Lefevere, A. (1985). Why Waste Our Time on Rewrites? The trouble with interpretation and the role of rewriting in an alternative paradigm. In T. Hermans, The Manipulation of Literature: Studies in Literary Translation (p. 215-243). New York: Routledge.

Lefevere, A. (1992). Translation, Rewriting and the Manipulation of Literary Fame. London \& New York: Routledge.

Machin, D. (2007). Introduction to Multimodal Analysis. London: Hodder Arnold.

Matthews, N., \& Moody, N. (2007). Judging A Book by Its Cover: Fans, Publishers, Designers, and the Marketing of Fiction. Aldershot, England: Ashgate Publishing.

Merriam-Webster Inc. (2004). Merriam Webster Dictionary Revised Edition. Massachusetts: Merriam-Webster Publishing company.

Milani, A. (2011). The Shah. New York, United States of America: St. Martin's Press.

Moran, D. (2001). Orwell's Animal Farm. New York: Hungry Minds, Inc.

Ning, W. (2003). Translation studies: Interdisciplinary approaches. Perspectives: Studies in Translation Theory and Practice, 11(1), 7-10. doi:10.1080/090767 6X.2003.9961457.

Orwell, G. (1945). Animal Farm. London: Secker and Warburg.

Orwell, G. (1969). Animal Farm. (A. Amirshahi, Trans.) Tehran: Franklin Publishing Center.

Orwell, G. (1982). Nineteen Eighty-Four. (S. Hosseini, Trans.) Tehran: Niloofar Publication.

Orwell, G. (2003). Animal Farm. (S. Hosseini, \& M. Nabi Zadeh, Trans.) Tehran: Doostan Publication.

Orwell, S., \& Angus, I. (1968). The Collected Essays, Journalism and Letters of George Orwell (Vols. IV: In Front of Your Nose 1945-1950). London, UK: Secker \& Warburg.

Ostovar, M. (2012). jij [The Color]. Tehran, Iran: Ketab Farsi.

Ožbot, M. (2015). Translation Studies - Interdisciplinary, Multidisciplinary or Transdisciplinary? Meta, 60(2), 360-360. doi:10.7202/1032911ar.

Parham, S. (2018, February 24). بدون كرايشات جب در بين روشنفكران مرتجع به حساب [without the left-wing tendencies, you were considered reactionary 
among intellectuals]. (M. Mortazavi, Interviewer) Tehran, Iran: Iran Book News Agency (IBNA). Retrieved March 05, 2018, from http://www.ibna.ir/fa/doc/ longint/258066/.

Salmani, B., \& Eghtesadi, Z. (2015, Jun). An Intersemiotic Approach towards Translation of Cover Designs in Retranslated Classic Novels. Theory and Practice in Language Studies, 5(6), 1185-1191. doi:10.17507/tpls.0506.09.

Samii, Z. (2014, July 01). زمانه/ /حتضار كتاب جيبي [The Dying Time of Jibi Books]. Retrieved April 25, 2018, from Tebyan: https://article.tebyan.net/280755/.

Schimmel, A., \& Soucek, P. P. (1992). Color Symbolism in Persian Literature. In E. Yarshater, Encyclopeedia Iranica (Vol. VI, p. 46-50). New York, United States of America: Columbia University Press. Retrieved from http://www.iranicaonline. org/articles/color-pers-rang.

Serafini, F., \& Clausen, J. (2012). Typography as Semiotic Resource. Journal of Visual Literacy, 31(2), 1-16. doi:10.1080/23796529.2012.11674697.

Shokri, A. (2011, January 6). حقوق برابر يا برابرتر آدم ها در جمهورى اسلامهى [Equal or More Equal Rights of People in the Islamic Republic]. (H. Zerehi, Ed.) Retrieved April 8, 2019, from تشهروند [Sharvand]: https://shahrvand.com/ archives/11648.

Sonzogni, M. (2011). Re-Covered Rose: A Case Study in Book Cover Design as Intersemiotic Translation. Amsterdam, The Netherlands: John Benjamins Publishing Company.

Torop, P. (2013). The ideological aspect of intersemiotic translation and montage. Sign Systems Studies, 41(2/3), 241-265. doi:10.12697/SSS.2013.41.2-3.07.

Van Dijk, T. A. (1998). Ideology: A multidisciplinary approach. New York: Sage.

Williams, J. (2013). Theories of Translation (1st ed.). London, UK: Palgrave Macmillan. [كتر صالح حسينب [Dr. Saleh Hosseini]. (n.d.). Retrieved February 06, 2018, from Shahid Chamran University of Ahvaz: http://portal.scu.ac.ir/HomePage. aspx?TabID $=4889 \&$ Site $=$ Lite.scu.ac\&Lang=fa-IR.

Recebido: $16 / 11 / 2018$

Aceito: $02 / 04 / 2019$ 